\title{
A new approach for the assessment of stochastic variation: analysis of behavioural response in blue mussel (Mytilus edulis L.)
}

\author{
D. L. Lajus \& A. A. Sukhotin \\ Zoological Institute; Universitetskaya nab. 1, 199034, St. Petersburg, Russia \\ E-mail: dlajus@popbio.zin.ras.spb.ru
}

\begin{abstract}
One of the most effective techniques for evaluating stress is the analysis of developmental stability, measured by stochastic variation based particularly on fluctuating asymmetry, i.e. a variance in random deviations from perfect bilateral symmetry. However, the application of morphological methods is only possible when an organism lives under testing conditions during a significant part of its ontogenesis. Contrary to morphological characters, behavior can change very fast. Consequently, methods based on behavioural characters may have advantages over more traditional approaches. In this study we describe the technique of assessing stochastic variation, using not morphological, but behavioural characters. To measure stochastic variation of behavioural response, we assessed the stability of the isolation reaction of blue mussel Mytilus edulis at regular changes of salinity. With increasing temperature from $+12^{\circ} \mathrm{C}$ to $+20^{\circ} \mathrm{C}$ stochastic variation of the isolation reaction increased, which is a common response to change of environmental conditions. In this way, we have developed a method of assessing stochastic variation of behavioural response in molluscs. This method may find a great range of applications, because its usage does not require keeping animals in tested conditions for a long time.
\end{abstract}

Key words: stochastic variation, behavioural response, blue mussel, Mytilus edulis

\section{INTRODUCTION}

Considerable attention has focused recently on the evaluation of stress in organisms by analysing their developmental stability (Leary \& Allendorf, 1989; Zakharov, 1989; Parsons, 1990; Zakharov \& Graham, 1992; Graham et al., 1993). Developmental stability is usually measured by assessing stochastic (intra-individual) variation. The most widely used method of assessing stochastic variation is based on the analysis of fluctuating asymmetry, i.e. the variance in random deviations from perfect bilateral symmetry. However, while morphological characters are analysed, application of this method is possible only if an organism lives in tested conditions during a significant part of its ontogenesis.

Contrary to morphological characters, behaviour can change very fast. Consequently, methods based on behavioural characters may have advantages over traditional approaches. The main objective of this work is to employ behavioural characters for the assessment of stochastic variation. 


\section{MATERIALS AND METHODS}

To estimate stochastic or intra-individual variation it is necessary to obtain replicate data from the same individual under the same conditions. Left and right manifestations of morphological bilaterally symmetrical characters can be considered as replicates because they are assumed to be genetically and environmentally identical. For behavior we can obtain replicate data, analysing several times the response of the same animal to the same effect under the same conditions.

In the present work we studied the isolation reaction of a bivalve mollusc, blue mussel Mytilus edulis. Our approach is based on the analysis of an organism's resistance under gradual changes of environmental factor, a method proposed by Fry (1971) for temperature experiments and later modified for analysis of salinity resistance of herring larvae (Ivanchenko \& Lajus, 1985). As salinity decreases to a certain critical point, molluscs isolate their mantle cavity by closing the edges of the mantle and later by closing the shell valves. Increasing salinity stimulates the opening of the shell and then of the mantle cavity and, finally, a continuation of pumping activity. Several experiments, which were carried out under the same conditions, were taken as replicates.

The location of our investigations in August 1994 was in Chupa Inlet (the White Sea). Mussels, 60 specimens in total, were collected from the intertidal zone. Length of animals varied from 25 to $31 \mathrm{~mm}$ and weight from 1.5 to $4.0 \mathrm{~g}$. Age was $6-8$ years. Mussels were kept in the laboratory at a salinity of $24 \%$ and temperature of $+12^{\circ} \mathrm{C}$, i.e. under conditions usually observed in the sea in this season.

Salinity was lowered by $1 \%$ per $10 \mathrm{~min}$ until all the mussels were closed (normally they were open). A mollusc was considered to be closed if the edges of its mantle were

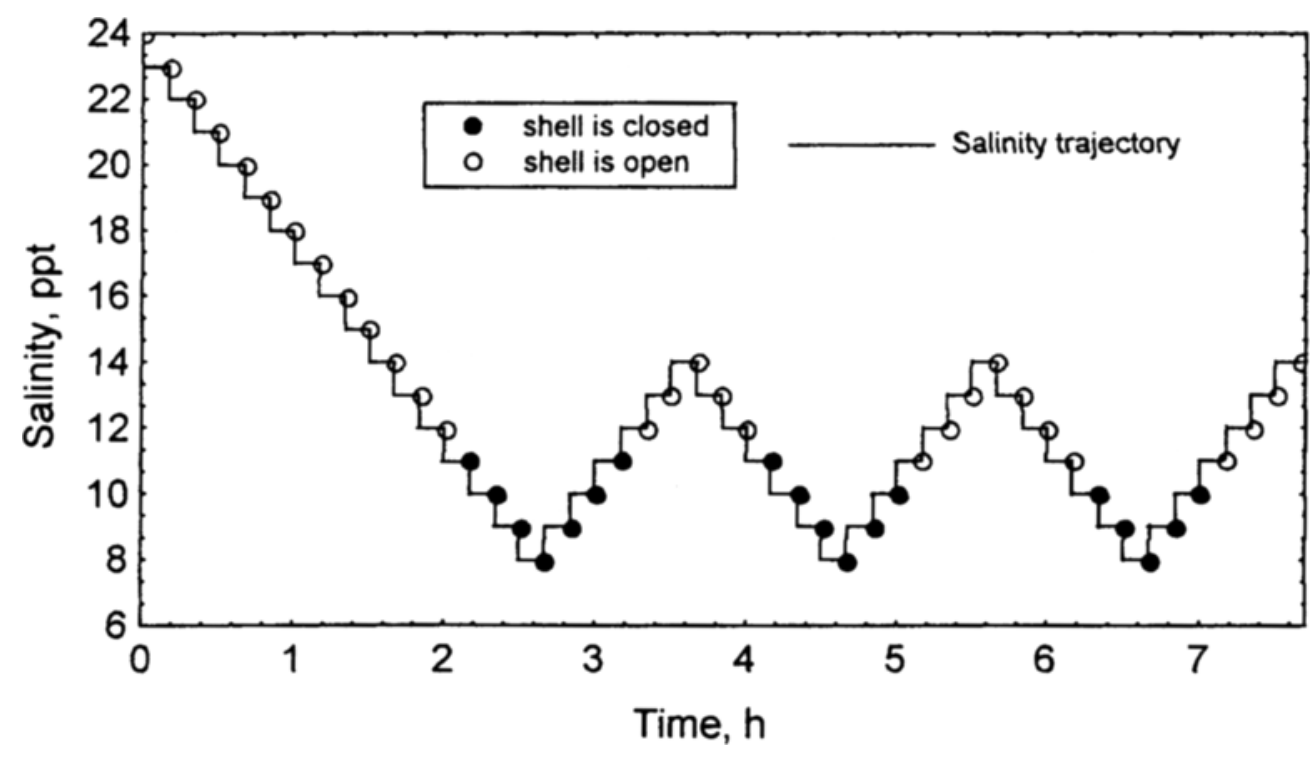

Fig. 1. Scheme of experiment for one mollusc 
not visible. Immediately after all molluscs closed, salinity was increased at the same rate until all the animals opened. Each trial contained two half-cycles (decreasing and increasing). One trial lasted for approximately 1.5 hours (Fig. 1). All 10 trials were conducted without intervals. Four intermediate trials were carried out at a temperature of $+20^{\circ} \mathrm{C}$. This temperature is not lethal for blue mussels. On the other hand it is not an optimal temperature, because the animals were acclimated to a temperature of $+12^{\circ} \mathrm{C}$.

As a result of this experiment we obtained the salinity values of closing and opening in each trial for all 10 trials for each of 60 specimens. Two figures were obtained for each trial: (1) mean value of salinity sensitivity, calculated by averaging the salinity sensitivity for two half-cycles and (2) stochastic variation (repeatability) of isolation reaction, calculated using the formula by Kozhara $(1989,1994)$ for bilateral characters:

$$
\mathrm{s}_{\mathrm{s}}^{2}=\Sigma\left[\left(\mathrm{S}_{\mathrm{c}}-\mathrm{m}_{\mathrm{c}}\right)-\left(\mathrm{S}_{\mathrm{o}}-\mathrm{m}_{\mathrm{o}}\right)\right]^{2 / 2 \mathrm{n},}
$$

where $S_{c}$ and $S_{o}$ are salinity of closing and opening within the same trial; $m_{c}$ and $m_{o}$ mean values of salinity of opening and closing for corresponding half-cycle; n number of specimens. Therefore, we did not use the initial data of closing and opening salinity, but the values corrected by subtracting the corresponding mean values. Use of corrected values instead of the initial ones allowed us to avoid artificially increasing the stochastic variation due to systematic difference between salinity of opening and closing (salinity of opening was usually about $0.3-0.5$ lower than salinity of closing).

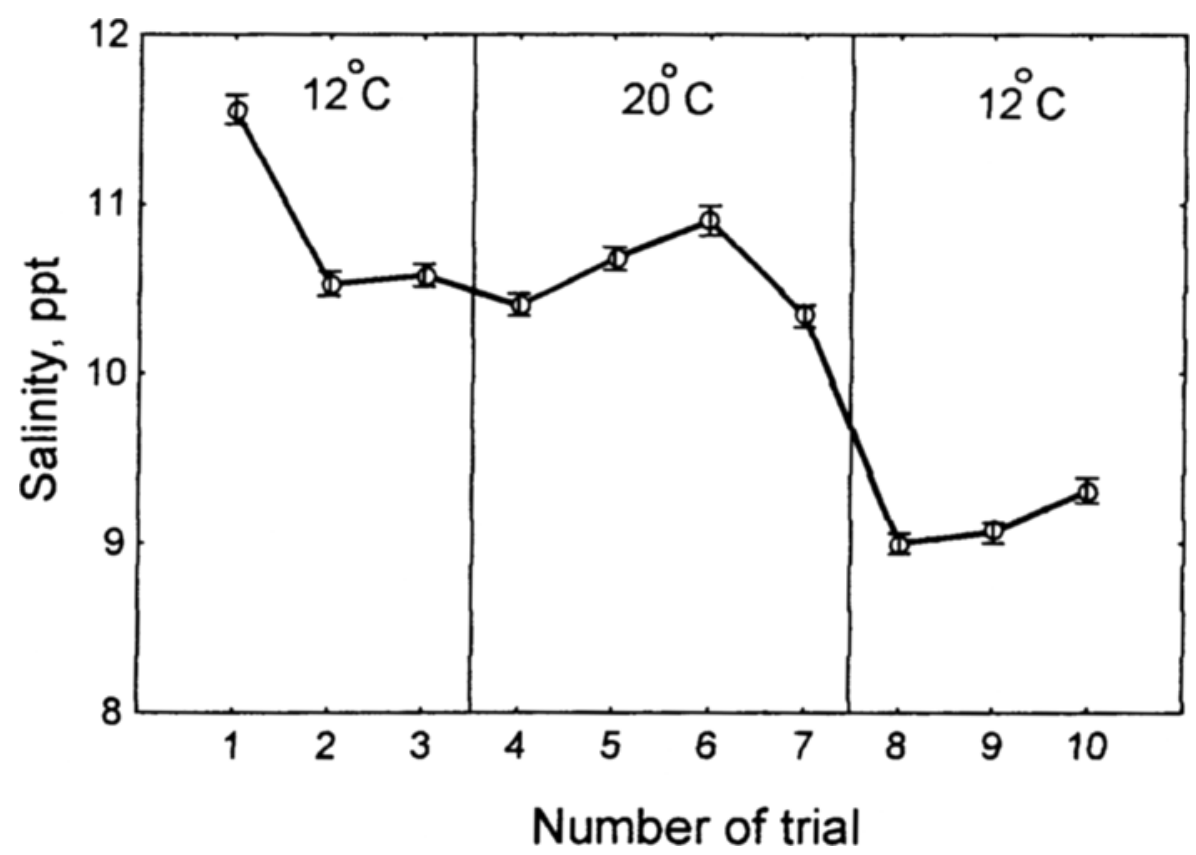

Fig. 2. Mean value of salinity sensitivity $( \pm S E, p=0.05)$ 


\section{RESULTS AND DISCUSSION}

The mean value of sensitivity of mussels during the first four trials (Fig. 2) can be interpreted as an acclimation to low salinity (salinity during the experiment was 9-12\%o, whereas before the experiment it was about $24 \%$ ). Increase of temperature up to $+20^{\circ} \mathrm{C}$ leads to an increase in sensitivity (trials 5 and 6 ), which is a common response to environmental changes. After reaching a maximum, sensitivity began to decrease (trials 7 and 8), probably due to acclimation of animals to increased temperature. Returning animals to the initial temperature $\left(+12^{\circ} \mathrm{C}\right)$ does not considerably affect the salinity sensitivity (trials 9 and 10).

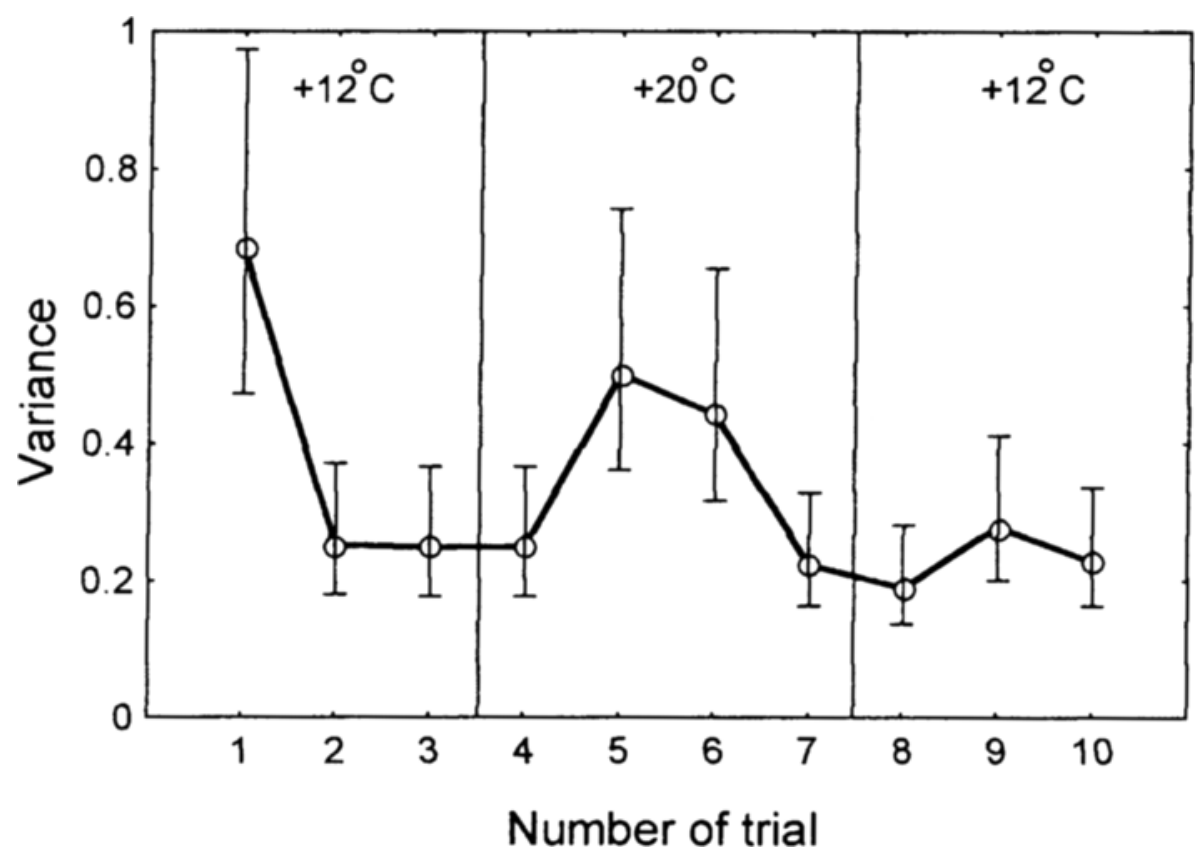

Fig. 3. Variance (repeatability, or stochastic variation) of salinity sensitivity ( $\pm \mathrm{SE}, \mathrm{p}=0.05$ )

Stochastic variation (Fig. 3) in the first trial is rather high. Its very fast decrease in the second trial is probably explained by adaptation of animals to the experiment regime. Constant values of stochastic variation in trials $2-4$ prompt us to suggest that these are inherent levels under these conditions. Stochastic variation essentially grows after the temperature increases [differences between trial 4 and 5 are statistically significant $(p<0.05)$ according to Fisher criterion]. Then it gradually decreases (trials 6-8), obviously reflecting the adaptation to new temperature conditions. At the final stage of the experiment, after returning animals to the initial temperature (trials 9 and 10), stochastic variation slightly increases, possibly responding to deviations of temperature from constant value. 
Thus, we have developed, for investigations on molluscs, a method of assessing the stochastic variation of behavioural response. It was demonstrated that, similar to morphological characters, stochastic variation of behavioural response increased with deviation of environmental conditions from the stable level. In this work we use temperature as a variable environmental factor. However, we suppose that a similar effect may be induced by other factors. Application of this method could be very wide, because its usage does not require keeping animals in tested conditions for a long time.

Acknowledgements. We would like to thank John Graham for valuable comments on the manuscript. We also acknowledge Vladimir Zakharov's helpful discussion of the results.

\section{LITERATURE CITED}

Fry, F. T. G., 1971. The effect of environmental factors on the physiology of fish. In: Fish physiology. Ed. by W. S. Hoar \& D. J. Randall. Acad. Press, New York, 6, 1-98.

Graham, J. H., Emlen, J. M. \& Freeman C. D., 1993. Developmental stability and its applications in ecotoxicology. - Ecotoxicology 2, 175-184.

Ivanchenko, O. F. \& Lajus, D. L., 1985. Resistance of the White Sea herring larvae and fries to low salinity. - Trudy zool. Inst. 179, 70-79.(In Russian).

Kozhara, A. V., 1989. On the ratio of components of phenotypic variances of bilateral characters in populations of some fishes. - Genetika (USSR) 25, 1508-1513. (In Russian).

Kozhara A. V., 1994. Phenotypic variance of bilateral characters as an indicator of genetic and environmental conditions in bream Abramis brama (L.) (Pisces, Cyprinidae) population. - J. appl. Ichth. 10,167-181.

Leary, R. F. \& Allendorf, F. M., 1989. Fluctuating asymmetry as an indicator of stress: implications for conservation biology. - Trends Ecol. Evolut. 4, 214-217.

Parsons, P. A., 1990. Fluctuating asymmetry: an epigenetic measure of stress. - Biol. Rev. 65, 131-145.

Zakharov, V. M., 1989. Future prospects for population phenogenetics. - Soviet scient. Rev. (sect. F), $4,1-79$.

Zakharov, V. M. \& Graham, J. H. (Eds.). 1992. Developmental stability in natural populations. - Acta zool. fenn. 191, 1-200. 